\title{
DESAIN KERAJINAN TAS ULOS BATAK KARYA SABINA COLLECTION
}

\author{
Sri Rahayu Fitriani ${ }^{1 *}$, Wahyu Tri Armojo ${ }^{2 *}$ \\ Program Studi Pendidikan Seni Rupa Jurusan Seni Rupa Fakultas Bahasa dan Seni \\ Universitas Negeri Medan \\ Jl. Willem Iskandar Pasar V Medan Estate, Kec, Percut Sei Tuan, Kab. Deli Serdang, Kode Pos 20371 \\ Sumatera Utara. Indonesia \\ Email:srirahayufitriani76@gmail.com,wahyu3mojo@yahoo.com
}

\begin{abstract}
Abstrak
Penelitian ini bertujuan untuk meninjau kerajinan tas berbahan kain ulos Batak dari indikator prinsipprinsip desain yang dilaksanakan di Sabina Collection. Penelitian ini merupakan penelitian deskriptif kualitatif. Subjek penelitian ini adalah 5 kerajinan tas berbahan kain ulos Batak produk Sabina Collection. Ketepatan penerapan prinsip-prinsip desain menjadi objek dalam penelitian ini, adapun bagian dari prinsip-prinsip desain adalah keas lian, kekinian, harmonisasi warna, inovatif dan finishing. Metode pengumpulan data yang digunakan adalah observasi, dokumentasi, dan wawancara. Analisis data yang digunakan yaitu teknik analisis deskriptif kualitatif. Hasil penelitian ini menunjukkan bahwa prinsip-prinsip desain kerajinan tas berbahan Kain ulos Batak pada produk Sabina Collection adalah baik. Ketepatan prinsip-prinsip desain pada produk kerajinan tas berbahan kain ulos Batak di Sabina Collection telah menunjukkan ketepatan yang baik pada indikator penilaian prinsip-prinsip desain dan juga sesuai dengan minat konsumen dan mendukung pelestarian kebudayaan daerah.
\end{abstract}

Kata Kunci: kerajinan, tas, ulos batak.

\begin{abstract}
This study aims to review the crafs made from Batak ulos cloth from the indicators design principles implemented in Sabina Collection. This research is a qualitative descriptive study. The subjects of this research were 3 crafts made from ulos Batak cloth from the Sabina Collection. The accuracy of the application of design principles in the object of this study, as for part of the design principles are original, up to date, color harmonization, innovation and finishing. Data collection methods used are observation, documentation, and interviews. Analysis of the data used is descriptive qualitative analysis techniques. The results of this study indicate that the design principles of the crafts made from Batak ulos cloth in the Sabina Collection products are good. The privisionof design principles in the crafts products made from the ulos Batak cloth collection has shown good accuraryon the indicatord of assessing design prinsiples and also in accordance with consumer interests and support the preservation of regional culture.
\end{abstract}

Keywords: crafts, bag, batak ulos.

\section{PENDAHULUAN}

Ulos Batak adalah salah satu hasil kerajinan tangan yang berasal dari Sumatera Utara. Ulos Batak merupakan kain adat Batak yang digunakan dalam upacara-upacara perkawinan, kematian, mendirikan rumah, kesenian, dan sebagainya. Kain ulos Batak ini terbuat dari benang kapas atau rami dengan berbagai macam corak, desain dan warna (hitam, putih dan merah). Tak hanya pengrajin kain ulos Batak, pembuat kerajinan juga memanfaatkan kain ulos Batak untuk dijadikan suatu produk yang memiliki nilai seni.

Kerajinan merupakan karya manusia yang berkaitan dengan keterampilan tangan dan memiliki nilai estetis, sehingga karya tersebut memiliki nilai jual. Karya kerajinan biasanya terbuat dari berbagai bahan dan

memiliki fungsi sebagai bahan hias maupun benda pakai. Berdas arkan hasil observasi peneliti, dilihat dari hasil karya prinsip-prinsip desain yang meliputi keaslian (original), kekinian (up to date), keharmonisan warna, inovatif yang dihasilkan dari kerajinan tas berbahan kain ulos Batak yang dihasilkan Sabina Collection masih terlihat kurang karena kemampuan dan pengetahuan pengrajin yang terbatas. Maka dari itu memerlukan pengetahuan mengenai prinsip-prinsip desain untuk membuat kerajinan tas dari kain ulos Batak. 
KAJIAN TEORI

\section{Desain}

Menurut Sembiring (2014:118) mengatakan bahwa Des ain diartikan juga sebagai penunjuk jalan atau pendekatan strategis untuk mencapai harapan yang unik. Pendekatan ini mendefinisikan spesifikasi, rencana, parameter, biaya, kegiatan, proses dan bagaimana serta apa yang harus dilakukan dalam batasan hukum, politik, sosial, lingkungan, keselamatan dan ekonomi dalam mencapai tujuan tersebut. Dalam hal ini sebuah "spesifikasi" dapat diwujudkan baik sebagai rencana atau gambaran awal produk jadi.

Crismianto (2017:59) menuliskan bahwa desain merupakan rancangan awal untuk membuat suatu, menentukan pola, ukuran, dan sebagainya agar hasil akhirnya dapat tercapai sesuai keinginan. Dalamdunia seni rupa di Indonesia, kata desain kerap dipadankan dengan reka bentuk, reka rupa, perencanaan, rangka, sketsa ide, gambar, merancang, meniru gambar, pemecahan masalah rupa.

Menurut Agus (2003:142) dalam dunia kesenirupaan Indonesia, kata desain kerapkali dipadankan dengan kata bentuk, tatarupa, rekayasa, perencanaan, gambar, hasil keterampilan, kary a kerajinan, kriy a penggayaan, ruang, menyusun, mencipta dan berbagaikegiatan yang berhubungan dengan kegiatan merancang dalam arti luas.

Berdasarkan beberapa pendapat di atas dapat disimpulkan bahwa desain adalah pola atau rancangan dengan melibatkan ketajaman perasaan atau feeling. Dan hal yang perlu diperhatikan untuk menciptakan suatu desain adalah sebuah ide.

\section{Kerajinan}

Menurut Raharjo (2011:16) mengatakan bahwa Kerajinan adalah suatu hal yang bernilai sebagai kreativitas alternatif, suatu barang yang dihasilkan melalui keterampilan tangan. Umumnya barang kerajinan banyak dikaitkan dengan unsur seni yang kemudian disebut seni kerajinan. Senikerajinan adalah implementasi dari karya seni kriya yang telah diproduksi secara massal (mass product). Selanjutnya Sembiring (2014:127) mengatakan bahwa "Seni kerajinan adalah cabang seni rupa yang perwujudan hasil jadinya sangat memerlukan kekeriyaan (craftsmanship) yang ting gi. Seni kerajinan juga sering diartikan sebagai seni "pekerjaan tangan" (handicraft)."
Gorga : Jurnal Seni Rupa

Volume 09 Nomor 02 Juli-Desember 2020 p-ISSN: 2301-5942 | e-ISSN: 2580-2380

Menurut Prasetya (2016:158) mengatakan bahwa "kerajinan diartikan sebagai pekerjaan yang dilakukan dengan tangan dan membutuhkan keterampilan tertentu". Selanjutnya menurut Graha (1998:3) mengatakan bahwa "kerajinan adalah kegiatan yang dilakukan secara manual dan artistik oleh pelakunya yang lazim disebut pengrajin".

Dari pengertian para ahli diatas dapat disimpulkan bahwa kerajinan adalah suatu kegiatan seni yang menggunakan keahlian tangan secara terus menerus guna menciptakan suatu produk yang bernilai ting gi dan bisa digunakan atau dimanfaatkan oleh mas yarakat.

\section{Ulos}

Menurut Emir dan Wattimena (2017:43) mengatakan bahwa Ulos secara harfiah berarti selimut yang memberikan kehangatan badan dari terpaan udara dingin bagi masyarakat Batak yang tinggal di daerah dataran tinggi. Sebelum masuknya budaya Barat, ulos merupakan pakaian sehari-hari masyarakat di tanah Batak. Sedangkan Menurut Nu'man (2017:78) meng atakan bahwa Kain ulos adalah salah satu kearifan lokal masyarakat Sumatera Utara atau Batak. Selain kain khas, ulos juga merupakan keunikan budaya yang tidak pernah terlupakan dalam menjalankan sebuah pesta atau perayaan tertentu di kalangan suku Batak.

Menurut Karmila (2010:45) mengatakan bahwa "Ulos adalah kain tradisional tenunan khas Batak. Ulos selalu digunakan dalamberbagai pesta dan upacara adat pada sub etnis Batak Toba.

Dari pengertian diatas dapat diambil kesimpulan bahwa ulos adalah sebuah kain tradisional khas Batak yang digunakan dalam keperluan adat dan merupakan salah satu ciri khas kebudayaan Batak.

\section{Kerajinan Tas Ulos}

Menurut Siregar (2017:1) mengatakan bahwa ulos sangat identik dengan suku Batak, dimana ada orang Batak disitu ada ulos. Ulos menjadi sarana adat dalam dalihan na tolu yang mengikat hubungan kekerabatannya. Hampir semua upacara adat-istiadat yang teradapat pada suku Batak harus menggunakan ulos sehingga wujud adat-istiadatnya ditunjukkan dalam ulos.

Namun seiring perkembangan zaman sekarang banyak yang menggunakan kain ulos bukan hanya untuk sebuah acara adat, namun untuk memperkenalkan kebudayaan Sumatera Utara lewat sebuah kerajinan tas yang dig abungkan dengan kain ulos Batak seperti yang 
dilakukan sebuah industri handmade "Sabina Collection" yang berlokasi di Helvetia, Komplek Pondok Surya Blok IV No. 139 Medan.

\section{Prinsip-prinsip Desain}

Menurut Karmila (2011:20), penyusunan berbagai unsur desain harus berdasar pada prinsip - prinsip des ain berikut:

\section{1). Kesatuan (Unity)}

Kesatuan adalah penyusunan/pengorganisasian unsurunsur desain sehingga menjadi s atu kesatuan yang utuh. Setiap unsur akan saling mendukung unsur yang lainnya, saling melengkapi dan saling mengisi s ehingga suatu karyas eni/desain dapatvtampil secara menarik.

\section{2). Keseimbangan (Balance)}

Keseimbangan dalam suatu desain karya seni tolak ukurnya adalah kepekaan estetis dan keseimbangan dari unsur-unsur desain itu sendiri. Suatu keseimbangan dalam karya seni dapat dicapai dengan mempertentangkan itu tidak harus selalu sama, seperti garis dengan garis atau warna dengan warna.

\section{3). Irama}

Dalam suatu kary a s eni, khususnya dalam suatu desain, irama dapat dibentuk melalui pengulangan (repetition) dan gerakan (movement) dari unaur-unsur desain yang bersifat visual yaitu garis, bidang, tekstur dan warna.

Menurut Saragih (2019:274) mengatakan bahwa prinsip-prinsip desain sebagai berikut: 1) Kes atuan, 2). Keseimbangan, dan 3). Irama.

\section{METODE PENELITIAN}

Metode penelitian yang digunakan yaitu metode penelitian deskriptif kualitatif. Teknik pengumpulan data yang digunakan observasi, wawancara dan dokumentasi. Ins trumen penelitian yang digunkan y aitu catatan report, kamera dan daftar pertanyaan. Teknik analis is data yang digunakan yaitu deskriptif kualitatif.

\section{HASIL DAN PEMBAHASAN \\ 1.Hasil}

Berdasarkan hasil pengamatan peneliti dan tinjauan karya kerajinan tas berbahan kain ulos Batak produk Sabina Collection yang dinilai berdasarkan indikator penilaian prinsip-prinsip desain diperoleh hasil bahwa ketiga karya tas berbahan kain ulos Batak dikategorikan baik.
Gorga : Jurnal Seni Rupa Volume 09 Nomor 02 Juli-Desember 2020 p-ISSN: 2301-5942 | e-ISSN: 2580-2380

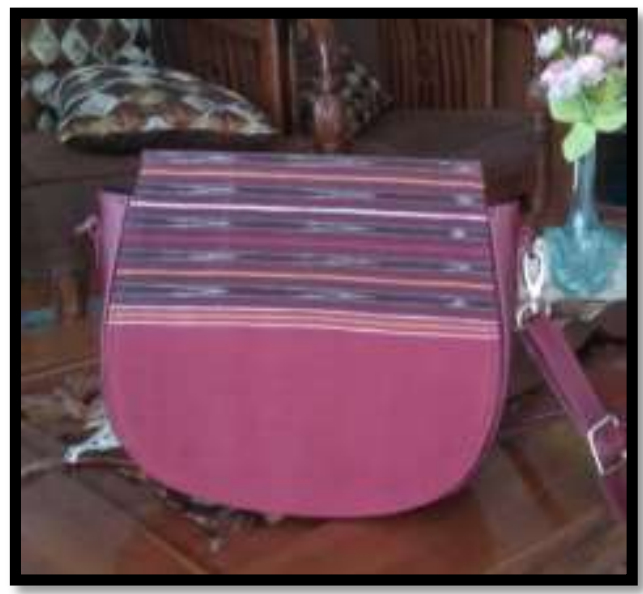

Gambar 1. Sling Bag Ulos Ragi Hotang (Fitriani, 2020)

Tabel 1. Hasil Penilaian Kerajinan Sling Bag Ulos Ragi Hotang

\begin{tabular}{|l|c|c|c|c|c|c|}
\hline $\begin{array}{c}\text { Aspek } \\
\text { Yang } \\
\text { dinilai }\end{array}$ & $\begin{array}{c}\text { Penilai } \\
1\end{array}$ & $\begin{array}{c}\text { Penilai } \\
2\end{array}$ & $\begin{array}{c}\text { Penilai } \\
3\end{array}$ & Jumlah & $\begin{array}{c}\text { Rata- } \\
\text { rata }\end{array}$ & ket \\
\hline $\begin{array}{l}\text { Keaslian } \\
\text { (original })\end{array}$ & 92 & 92 & 94 & 278 & 93 & $\mathrm{~A}$ \\
\hline $\begin{array}{l}\text { Kekinian( } u \\
\text { p to date })\end{array}$ & 95 & 94 & 95 & 284 & 95 & $\mathrm{~A}$ \\
\hline Warna & 86 & 88 & 84 & 258 & 86 & $\mathrm{~B}$ \\
\hline Inovatif & 90 & 90 & 90 & 270 & 90 & $\mathrm{~A}$ \\
\hline Finishing & 90 & 92 & 92 & 274 & 91 & $\mathrm{~A}$ \\
\hline Jumlah & & & & & $\mathbf{4 5 5}$ & \\
\hline Rata-rata & & & & & $\mathbf{9 1}$ & $\mathbf{A}$ \\
\hline
\end{tabular}

\section{2). Tote Bag Ulos Sadum}

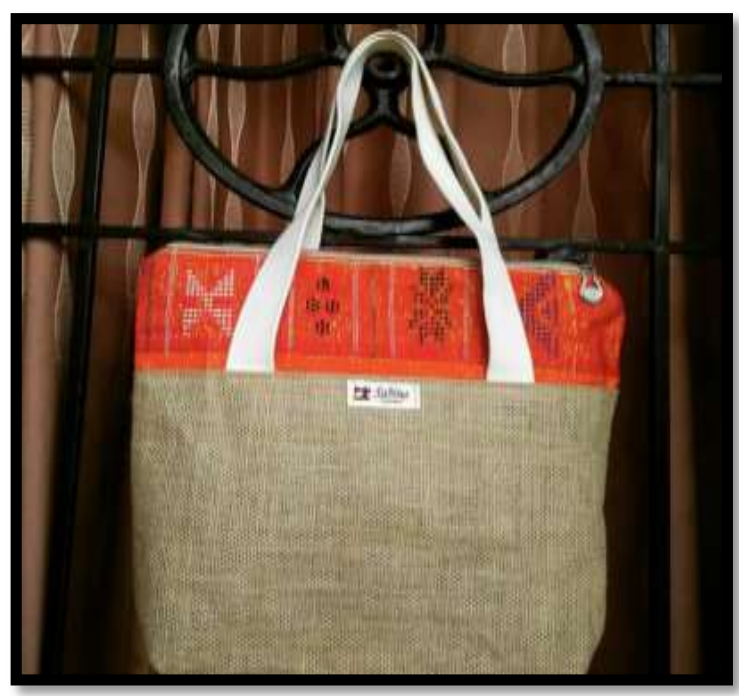

Gambar 2. Tote Bag Ulos Sadum (Fitriani, 2020)

\section{1). Sling Bag Ragi Hotang}


Tabel 2. Hasil Penilaian Kerajinan Tote Bag Ulos Sadum

\begin{tabular}{|l|c|c|c|c|c|c|}
\hline $\begin{array}{c}\text { Aspek } \\
\text { Yang } \\
\text { dinilai }\end{array}$ & $\begin{array}{c}\text { Penilai } \\
1\end{array}$ & $\begin{array}{c}\text { Penilai } \\
2\end{array}$ & $\begin{array}{c}\text { Penilai } \\
3\end{array}$ & $\begin{array}{c}\text { Juml } \\
\text { ah }\end{array}$ & $\begin{array}{c}\text { Rata- } \\
\text { rata }\end{array}$ & ket \\
\hline $\begin{array}{l}\text { Keaslian } \\
\text { (original) }\end{array}$ & 84 & 85 & 87 & 256 & 85 & B \\
\hline $\begin{array}{l}\text { Kekinian } \\
\text { (up to } \\
\text { date) }\end{array}$ & 85 & 86 & 84 & 255 & 85 & B \\
\hline Warna & 86 & 85 & 83 & 254 & 85 & B \\
\hline Inovatif & 83 & 84 & 85 & 252 & 84 & B \\
\hline Finishing & 85 & 86 & 86 & 257 & 86 & B \\
\hline Jumlah & & & & & 425 & \\
\hline Rata-rata & & & & & 85 & B \\
\hline
\end{tabular}

\section{3). Tas Laptop Ulos Sadum}

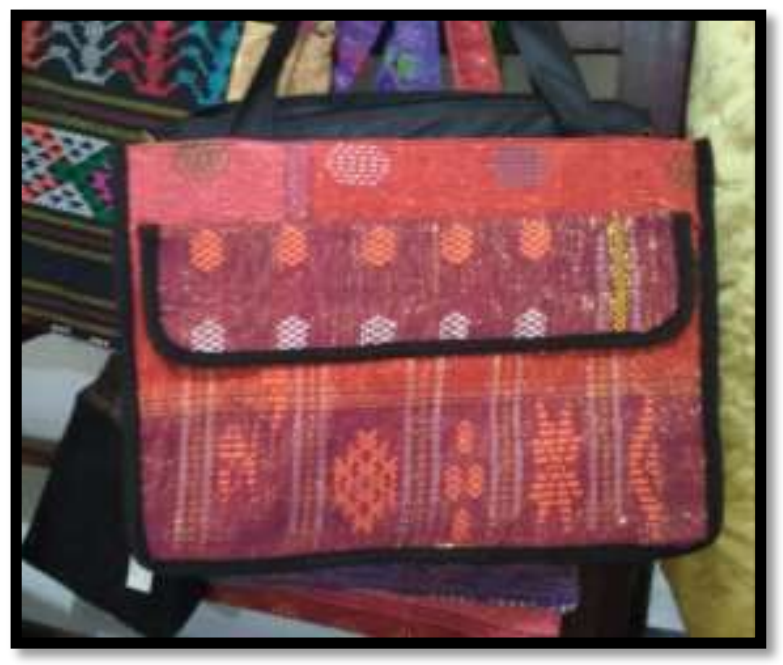

Gambar 3. Tas Leptop Ulos Sadum (Fitriani, 2020)

Tabel 3. Hasil Penilaian Kerajinan Tas Leptop Ulos Sadum

\begin{tabular}{|l|c|c|c|c|c|c|}
\hline $\begin{array}{c}\text { Aspek } \\
\text { Yang } \\
\text { dinilai }\end{array}$ & $\begin{array}{c}\text { Penilai } \\
1\end{array}$ & $\begin{array}{c}\text { Penilai } \\
2\end{array}$ & $\begin{array}{c}\text { Penilai } \\
3\end{array}$ & Jumlah & $\begin{array}{c}\text { Rata- } \\
\text { rata }\end{array}$ & ket \\
\hline $\begin{array}{l}\text { Keaslian } \\
\text { (original })\end{array}$ & 87 & 86 & 88 & 261 & 87 & B \\
\hline $\begin{array}{l}\text { Kekinian }(u \\
\text { to date })\end{array}$ & 85 & 85 & 85 & 255 & 85 & B \\
\hline Warna & 81 & 82 & 83 & 246 & 82 & B \\
\hline Inovatif & 83 & 84 & 85 & 252 & 84 & B \\
\hline Finishing & 88 & 88 & 86 & 262 & 87 & B \\
\hline Jumlah & & & & & $\mathbf{4 2 5}$ & \\
\hline Rata-rata & & & & & $\mathbf{8 5}$ & B \\
\hline
\end{tabular}

\section{Pembahasan}

\section{1). Sling Bag Ulos Ragi Hotang}

Setelah data dari penilai dikumpulkan dan dianalisis secara umum maka diketahui kerajinan tas ulos Batak pada sling bag ulos ragi hotang ditinjau dari prinsipprinsip desain mendapat predikat nilai sangat baik dengan jumlah nilai $=455$ dengan rata-rata $(r)=91$ (sangat baik).

Jika dideskripsikan berdasarkan aspek penilaian prinsip-prinsip desain maka aspek keaslian (original) memperoleh nilai rata-rata $(r)=93$ (sangat baik)
Gorga : Jurnal Seni Rupa

Volume 09 Nomor 02 Juli-Desember 2020

p-ISSN: 2301-5942 | e-ISSN: 2580-2380

dengan penjelasan keaslian (original) yaitu ide dan gagasan yang berasal dari kreatifitas pengrajin. Pembuatan desain kerajinan tas ulos Batak dirancang oleh pengrajin. Desain dibuat berdasarkan melihat desain tas pada umumnya hanya saja ada penambahan kain ulos ragi hotang dan kerajinan tas dibuat tanpa menghilangkan nilai etnik budaya Sumatera Utara.

Aspek selanjutnya adalah kekinian (up to date) dengan nilai rata-rata $(\mathrm{r})=95$ (sang at baik) deng an penjelasan pada kerajinan terlihat baru karena memodifikasikan dengan kain ulos Batak ragihotang dengan bahan dasar kulit imitasi. Kerajinan tas ulos Batak didesain dengan mengikuti perkembangan zaman dan minat mas yarakat umumnya wanita. Namun masih mempertahankan nilai etnik dari budaya Batak.

Berikutnya adalah aspek warna dengan nilai rata-rata $(\mathrm{r})=86$ (baik) dengan penjelasan keselarasan penggabungan bahan dasar kain ulos Batak. Terdapat bahan dasar pada kerajinan tas yaitu bahan kulit sintesis berwarna merah dengan kain ulos ragi hotang berwarna merah. Pada kain ulos ragi hotang terdapat garis berwarna putih, merah dan kuning. Warna pada kain ulos ragi hotang untuk memberi kesan warna tas agar tidak monoton dan menambah nilai etnik pada kerajinan sling bag ulos Batak.

Kemudian as pek inovatif dengan nilai rata-rata $(r)=90$ (sang at baik) dengan penjelasan pada kerajinan tas ulos Batak terdapat pembaruan desain pada kerajinan sling bag karena menggunakan bahan dasar kain ulos ragi hotang yang dikombinasikan dengan bahan kulit sintesis, pada bagian tas lebih diperlihatkan motif kain ulos sadumagak ciri khas dari kain ulos sadumsendiii tidak hilang.

Aspek as pek penilaian yang terakhir adalah finishing dengan rata-rata $(r)=91$ (sangat baik) dengan penjelasan tampilan kain ulos sadum yang sudah dijadikan sling bag terlihat rapi dengan penambahan bahan dasar kulit sintesis warna merah pada sling bag yang dilengkapi dengan warna dari motif kain ulos sadum deng an garis berwarna putih,merah dan kuning dari kain ulos sadum. Ukuran pada sling bag ulos sadum sedang (madium) karena bisa ditujukan untuk ke acara formal atau informal.

Berdasarkan pemaparan nilai rata-rata dari tim penilai dan analisis berdasarkan landasan teori y ang digunakan maka kerajinan sling bag kain ulos sadummemperoleh kategori sangat baik.

\section{2). Tote Bag Ulos Sadum}

Setelah data dari penilai dikumpulkan dan dianalisis secara umum maka diketahui kerajinan tas ulos Batak pada tote bag ditinjau dari prinsip-prinsip desain mendapat predikatnilai baik deng an jumlah nilai $=425$ dengan rata-rata $(r)=85$ (baik). 


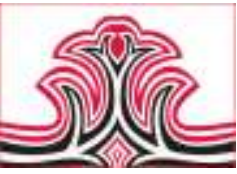

Jika dideskripsikan berdasarkan aspek penilaian prinsip-prinsip desain maka aspek keaslian (original) memperoleh nilai rata-rata $(r)=85$ (baik) dengan penjelasan keaslian (original) yaitu ide dan gagasan yang berasal dari kreatifitas pengrajin. Pembuatan desain kerajinan tas ulos Batak dirancang oleh pengrajin. Desain dibuat berdasarkan melihat desaintas pada umumnya hanya saja ada penambahan kain ulos sadum dan serta mengkombinasikan dengan bahan yang unik yaitu kain goni kerajinan tas dibuat tanpa menghilangkan nilai etnik budaya Sumatera Utara.

Aspek selanjutnya adalah kekinian (up to date) dengan nilai rata-rata $(r)=85$ (baik) dengan penjelasan pada kerajinan terlihat baru karena memodifikasikan dengan kain ulos sadum dengan bahan dasar kain goni. Kerajinan tote bag kain ulos sadum didesain dengan mengikuti perkembangan zaman dan memperlihatkan keunikan pada tas yaitu kombinasi dengan bahan kain goni. Namun masih mempertahankan nilai etnik dari budaya Batak.

Berikutnya adalah as pek warna dengan nilai rata-rata $(r)=85$ (baik) dengan penjelasan keselarasan penggabungan bahan dasar kain ulos Batak. Terdapat bahan dasar pada kerajinan tas yaitu bahan kain goni berwarna coklat dengan kain ulos sadum berwama merah. Pada kain ulos Sadum yang berwarna merah lebih dominan dibandingkan warna pada bahan dasar kain goni berwarna coklat. Sehingga motif dari kain ulos Sadum dapat diperlihatkan lebih menonjol dibandingkan bahan dasar tas.

Kemudian as pek inov atif dengan nilai rata-rata $(r)=84$ (baik) dengan penjelasan pada kerajinan tas ulos Batak terdapat pembaruan desain pada kerajinan tote bag karena menggunakan bahan dasar kain ulos sadum yang dikombinasikan dengan bahan kain goni, pada bagian tas lebih ditonjolkan motif kain ulos sadum dibandingkan bahan dasar kain goni agar ciri khas dari kain ulos sadum sendiri tidak hilang. Tote bag dengan bahan kain goni memiliki ciri khas keunikan sendini dibandingkan tas yang lain yang pada umumnya menggunakan bahan kulit sintesis.

Aspek as pek penilaian yang terakhir adalah finishing dengan rata-rata $(r)=86$ (baik) dengan penjelasan tampilan kain ulos sadumyang sudah dijadikan totebag terlihat rapi dan unik dengan penambahan bahan dasar kain goni berwarna coklat yang dilengkapi dengan warna dari kain ulos sadumyaitu warna merah dengan motif berwarna putih, hitamdan kuning y ang membuat tote bag menjadi unik dan warna tidak monoton karena adanya perbedaan warna pada tote bag. Ukuran pada
Gorga : Jurnal Seni Rupa

Volume 09 Nomor 02 Juli-Desember 2020

p-ISSN: 2301-5942 | e-ISSN: 2580-2380

tote bag ulos sadum besar karena ditujukan untuk umum.

Berdas arkan pemaparan nilai rata-rata dari tim penilai dan analisis berdasarkan landasan teori y ang digunakan maka kerajinan tote bag kain ulos sadum memperoleh kategori baik.

\section{3). Tas Laptop Ulos Sadum}

Setelah data dari penilai dikumpulkan dan dianalisis secara umum maka diketahui kerajinan tas ulos Batak pada tas leptopulos sadum ditinjau dari prinsip-prinsip desain mendapat predikat nilai sangat baik dengan jumlah nilai $=425$ dengan rata-rata $(r)=85$ (baik).

Jika dideskripsikan berdasarkan aspek penilaian prinsip-prinsip desain maka aspek keas lian (original) memperoleh nilai rata-rata $(\mathrm{r})=87$ (baik) dengan penjelasan keas lian (original) yaitu ide dan gagasan yang berasal dari kreatifitas pengrajin. Pembuatan kerajinan tas ulos Batak dirancang oleh pengrajin dengan memikirkan kegunaan tas serta manfaat yang didapat dalam melestarikan kebudayaan Batak lewat tas leptop. Des ain tas laptop ada penambahan kain ulos sadum dan kerajinan tas dibuat tanpa menghilangkan nilai etnik budaya Batak.

As pek selanjutnya adalah kekinian (up to date) dengan nilai rata-rata $(r)=85$ (baik) dengan penjelasan pada kerajinan terlihat baru karena memodifikasikan dengan kain ulos Batak sadumdengan bahan dasar kain dengan tekstur lembut dan berkualitas baik yang akan digunakan untuk tempat menyimpan laptop. Kerajinan tas ulos Batak didesain dengan mengikuti perkembangan zaman dan bertujuan untuk menarik minat masyakat terhadap kebudayaan Batak. Namun pengrajin masih tetap mempertahankan nilai etnik dari budaya Batak.

Berikutnya adalah aspek warna dengan nilai rata-rata (r) = 82 (baik) dengan penjelasan keselarasan penggabungan bahan dasar kain ulos sadum Batak. Terdapat bahan das ar pada kerajinan tas yaitu bahan kain ulos sadum Batak dengan corak warna merahdengan perpaduan warna hitam pada pinggiran tas dan di kombinasi dengan berbagai motif yang berwarna putih, kuning dan merah. Warna motif pada kain ulos sadumuntuk memberi kes an warna tas leptop agar tidak monoton karena pada dasar kain ulos sadum hanya terdapat warna merah sehingga terkesan seperti monoton.

Kemudian as pek inovatif dengan nilai rata-rata (r) $=84$ (baik) dengan penjelasan pada kerajinan tas ulos Batak 
terdapat pembaruan desain pada kerajinan tas leptop karena menggunakan bahan dasar kain ulos sadum yang dikombinasikan dengan motif yang menarik, pada bagian tas lebih ditonjolkan motif kain ulos sadumagar ciri khas dari kain ulos sadumsendiritidak hilang. Tas leptop kain ulos sadum dibuat berdasarkan kebutuhan masyarakat dalam menggunakan leptop dan untuk ajang memperkenalkan kain ulos sadum dimasyarakat agarikut serta dalammelestarikan kebudayaan Batak.

Aspek penilaian yang terakhir adalah finishing dengan rata-rata $(r)=85$ (baik) dengan penjelasan tampilan kain ulos sadumyang sudah dijadikan tas leptop. Pada luar kerajinan tas leptop tidak menggunakan bahan das ar hanya menggunakan kain ulos sadum. Terlihat pada bagian luar tas leptop terdapat slot lain untuk meletakkan barang yang menambah nilai guna. Motif kain ulos sadum pada tas leptop berwarna merah dengan motif y ang berwarna jingga (orange), putih dan kuning. Ukuran pada tas leptop ulos sadum sesuai dengan ukuran laptop.

Berdas arkan pemaparan nilai rata-rata dari tim penilai dan analis is berdasarkan landasan teori yang digunakan maka kerajinan tas leptop kain ulos sadummemperoleh kategori baik.

\section{KESIMPULAN DAN SARAN 1.Kesimpulan}

Berdas arkan hasil penelitian y ang telah diperoleh maka dibuat kesimpulan dari hasil penelitian secara keseluruhan berdasarkan variabel-variabel yang diteliti. Adapun kesimpulan pada aspek Keaslian (original) yaitu dalam pembuatan kerajinan tas ulos Batak yang terdiri dari sling bag, tote bag, clutch bag, hobo bag dan tas leptop merupakan ide atau gagasan karya yang diciptakan sendiri oleh pengrajin. Dan perencanaan pembuatan desain kerajinan tas dilakukan sendiri dengan melihat kegunaan dari tas. Sehingga keaslian (original) memperoleh kategori baik. Kemudian pada aspek kekinian (up to date) yaitu kerajinan tas dengan penggabungan kain ulos Batak merupakan kerajinan baru/kekinian dan mengikuti perkembangan zaman karena tas didesain dengan mengikuti perkembangan minat masyarakat terutama dikalangan perempuan. Sehing ga kekinian (up to date) memperoleh kategori baik. Lalu pada aspek keharmonisan Warna dimana merupakan kerajinan tas ulos Batak yang memiliki berbagai variasi warna, namun karena adanya perbedaan warna antara bahan das ar dan motif dari kain u los Batak membuat kerajinan tas ulos Batak terlihat selaras dan tidak monoton. Keharmonisan warna memperoleh kategori baik. Selanjutnya pada aspek inovatif adanya pembanan
Gorga : Jurnal Seni Rupa

Volume 09 Nomor 02 Juli-Desember 2020

p-ISSN: 2301-5942 | e-ISSN: 2580-2380

desain dalam perwujudan bentuk kerajinan tas ulos Batak dapat dilihat dari segi bentuk dan bahan dasar, serta penambahan kain ulos Batak yang disesuaikan dengan bahan dasar tas. Kerajinan tas ulos Batak juga dibuat untuk melestarikan kebudayaan Batak. Sehingga inovatif memperoleh kategori baik. Kemudian yang terakhir pada as pek Finishing yaitu tampilan pada kain ulos Batak yang sudah dijadikan tas ulos Batak selaras dengan warna bahan dasartas maupun kain ulos Batak. Sehingga kerajinan tas yang sudah jadi memiliki keunikan yang mencerminkaan kebudayaan Sumatera Utara terutama kebudayaan Batak. Sehingga finishing memperoleh kategori baik.

\section{Saran}

Berdasarkan kesimpulan dari hasil penelitian, maka peneliti memberikan beberapa saran yaitu pengrajin diharapkan lebih mempelajari tentang teori prinsipprinsip desain agar karya yang dihasilkan lebih baik lagi. Pengrajin diharpkan memperluas pengetahuan dengan banyak melihat desain lain atau desain yang unik. Kemudian memperlihatkan warna dasar tas dan warna kain ulos Batak agar warnay ang diciptakan tidak monoton dan menarik perhatian masyarakat. Lalu pengrajin diharapkan menciptakan desain kerajin an tas ulos Batak yang tidak ditemukan dipengrajin lain, desain tas yang dibuat harus tetap melestarikan kebudayaan Batak. Sehingga dapat menarik lebih banyak minat masyarakat terhadap produk lokal dan ikut serta melestarikan kebudayaan Batak.

\section{DAFTAR RUJUKAN}

Agus, Sachari. (2003). Estetika Terapan: Spirit-Sepirit yang Menikam Desain. Bandung: Penerbit Nova.

Emir, Threes dan Wattimena, Samuel. (2017). Kain Ulos Danau Toba. Jakarta: Gramedia Pustaka Utama.

Fitriani, S. R. (2020). "Kumpulan Karya Ulos Batak". Hasil Dokumentasi Pribadi: 09 Agustus 2020, Sabina Collection.

Graha, Oho, (1998). Pokok-pokok Pengajaran Kerajinan Tangan dan Kesenian. Jakarta: Departeman Pendidikan dan Kebudayaan.

Karmila, Mila \& Marlina. (2011). Kriya Tekstil. Jakarta: Bee Media Indonesia.

Karmila, Mila. (2010). Ragam Kain Tradisional Nusantara: (Makna, Simbol, dan Fungsi). Jakarta: Bee Media Indonesia.

Nu'man, Baihaqi. (2017). Jelajah Sumatera: Keagungan Seni dan Budaya. Surakarta: PT Borobudur Inspira Nusantara.

Prasetya, Eka Rima. (2016). Pengembangan Modul Prakarya dan Kewirausahaan Materi 
Kerajinan Berbasis Proses Di SMK. Jurnal

Pendidikan Vokasi, 6(2), 154-161.

Raharjo, Timbul. (2011). Seni Kriya dan Kerajinan.

Tes is tidak diterbitkan. Yogyakarta: Program

Pasca Sarjana ISI Yogyakarta.

Saragih, Lisa Andriani. (2019). Analisis Kerajinan

Souvenir Diorama Berbahan Limbah Pada Pengrajin Dikraf Berdasarkan PrinsipPrinsip Desain. Gorga: Jurnal Seni Rupa, 8(1), 273-278.

Sembiring, Dermawan. (2014). Wawasan Seni. Medan: Unimed Press.

Siregar, M. (2016). Industri Kreatif Ulos Pada Masyarakat Pulau Samosir. Jurnal Studi Kultural, 2(1), 1-5. 